\title{
Monitoring and Modelling of the Energy Consumption in Polymer Extrusion
}

\author{
Document Version \\ Submitted manuscript
}

Link to publication record in Manchester Research Explorer

\section{Citation for published version (APA):}

Abeykoon, C., Kelly, A. L., Vera-Sorroche, J., Brown, E. C., \& Coates, P. D. (2014). Monitoring and Modelling of the Energy Consumption in Polymer Extrusion. In host publication (pp. 1030-1035)

\section{Published in:}

host publication

\section{Citing this paper}

Please note that where the full-text provided on Manchester Research Explorer is the Author Accepted Manuscript or Proof version this may differ from the final Published version. If citing, it is advised that you check and use the publisher's definitive version.

\section{General rights}

Copyright and moral rights for the publications made accessible in the Research Explorer are retained by the authors and/or other copyright owners and it is a condition of accessing publications that users recognise and abide by the legal requirements associated with these rights.

\section{Takedown policy}

If you believe that this document breaches copyright please refer to the University of Manchester's Takedown Procedures [http://man.ac.uk/04Y6Bo] or contact uml.scholarlycommunications@manchester.ac.uk providing relevant details, so we can investigate your claim.

\section{OPEN ACCESS}




\title{
Monitoring and Modelling of the Energy Consumption in Polymer Extrusion
}

\author{
Chamil Abeykoon, Adrian L. Kelly, Javier Vera-Sorroche, Elaine C. Brown, Phil D. Coates
}

\begin{abstract}
Extrusion is one of the fundamental methods in polymer processing and is involved in the production of various commodities in diverse industrial sectors. Being an energy intensive production method, process energy efficiency is one of the major concerns and the selection of the most energy efficient processing conditions is a key to reduce operating expenses. Usually, extruders consume energy through the drive motor, barrel heaters, cooling fans, cooling water pumps, gear pumps, etc. Typically the drive motor is the dominant energy consuming device in a polymer processing extruder while barrel/die heaters are responsible for the second largest energy demand. This study was focused on investigating the total energy demand of an extrusion plant while identifying ways to optimise the energy consumption. Total energy consumption of a single screw extruder was measured over different processing conditions and then modelled as a function of a number of major process variables. The results show that the extruder energy demand is heavily coupled with machine, material and process parameters. Also, the proposed models show excellent agreement with the experimental measurements and hence these should be useful in optimising process energy efficiency.
\end{abstract}

Index Terms - Polymer extrusion, Process monitoring, Energy consumption, Energy efficiency, Power factor, Modelling.

\section{INTRODUCTION}

Polymers are among the most important materials available to the manufacturing industry. Many conventional raw materials such as steel, glass and wood are being replaced by various types of polymeric materials/composites which perform the same function while offering a number of other advantages. As a result, the demand for polymers has shown a rapid increase over the last few decades. Records show that the world total plastic production in the 1950, 1976, 1989, 2002 and 2010 was 1.3, 50, 100, 200 and 304 millions of tonnes, respectively [1]. Moreover, the world plastics production in volume surpassed that of steel production in 1981 and the gap has been continuously increasing since then [2]. Such an increasing demand for polymers is due to their some of the superior properties such as ease of forming into complex shapes; high strength to weight ratio; corrosion resistance; clarity; low cost; etc. The demand for polymeric materials is forecast to further increase in future as well.

\section{A. Polymer extrusion}

Currently, various types of polymer processing extruders are available in industry: single/multi screw extruders, disk/drum extruders, etc. Of these extruders, single screw continuous extruders are the most commonly used

C. Abeykoon is with the School of Engineering and Applied Physics, Glyndwr University, Wrexham, LL11 2AW, UK, E-mail: c.abeykoon@glyndwr.ac.uk, yabeykoon01@qub.ac.uk

A. L. Kelly, J. Sorroche, E. C. Brown and P. D. Coates are with the IRC in Polymer Science and Technology, University of Bradford, Bradford, BD7 1DP, UK in the plastics industry. The screw is the key component of an extruder and can be divided into three main functional/geometrical zones (i.e. feed or solids conveying, compression or melting, and metering or melt conveying) in the case of simple, single flighted screw geometries based on its primary operations. The feedstock material fed into the machine through the hopper is conveyed along the screw while absorbing the heat provided by the barrel heaters and through process mechanical work. Eventually, a molten flow of material is forced into the die which forms the melt into the desired shape. More details on the process mechanisms of polymer extrusion can be found in the literature [3], [4].

Being a fundamental method of processing of polymeric materials, extrusion is involved in the production of commodities in diverse industrial sectors such as packaging; household; automotive; aerospace; marine; construction, etc. In fact, extrusion is an energy intensive production method. Although the process energy efficiency is good at higher speeds, it is difficult to run the processes at high speeds as thermal fluctuations increase with the processing speed resulting in very poor melt quality. Therefore, the majority of extrusion processes are operating at conservative rates to control/avoid problematic thermal fluctuations and this leads to poor energy efficiency conditions. Additionally, energy prices are increasing rapidly and a worldwide energy crisis is predicted. Hence, plastics based manufactures are highly concerned about the energy efficiency of their production plants to achieve the expected profit margins. Thus, there is a major concern in the current industry of how to optimise energy and thermal efficiency, both at the same time, while achieving the required process output rate and melt quality.

\section{B. Extruder energy consumption}

Usually, extruders are supplied with the electrical energy for their operation and this energy is converted into the forms of mechanical or thermal energy. Then, the energy losses occur in the several stages of its operation majorly as electrical, mechanical or thermal losses. A typical energy flow diagram for an extruder is shown in Figure 1 (not drawn to scale). Currently, most extruders are driven by

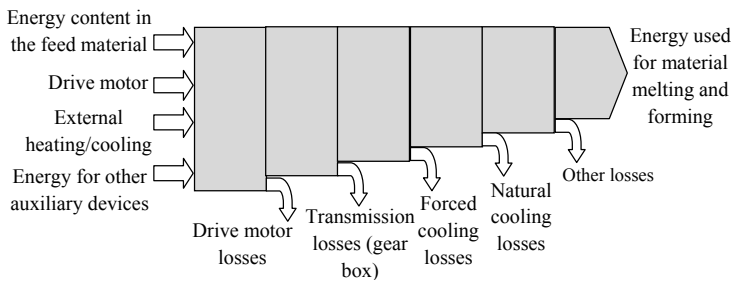

Fig. 1. A typical energy flow diagram for an extruder 
alternating current (AC) or direct current (DC) motors. In a typical AC motor, energy losses usually occur as electrical (or copper), core, mechanical and stray losses. In addition to these four types of losses, brush loss occurs in DC motors which use brushes for supplying the power [5]. Usually, electrical motors are inductive loads (as they use magnetic fields) and the power demand is related to the power factor (i.e. ranges from 0 to 1 ) which has some effect on energy efficiency. More details relating to the extruder drive motor were discussed by the authors previously [6], [7].

The heat removed by the barrel/die/screw cooling mechanisms comes under the forced cooling losses while natural cooling losses may happen via radiation and convection across the surfaces exposed to the surroundings. The energy losses which may take place in the rectifier, water pumps, instrument panel and other auxiliary devices can be categorized under other energy losses. Obviously, the actual amount of total energy input and loss are dependent upon factors such as the size/age/type of the machine, processing conditions, material being processed, skills/knowledge of the operator, and so forth. Some of the previous studies reported in the literature on extruder energy are now discussed.

Kruder and Nunn [8] reported that the typical extruder energy efficiency ranges from about $45 \%$ to $75 \%$. They argued that the extruder energy efficiency depends on factors such as screw design, gearing, polymer feedstock, product geometry and extrusion rate. As they believed, the major energy losses of an extruder occur via the drive train and forced cooling. Moreover, the authors argued that the barrel heaters are the dominant energy input source at low screw speeds. Also, the operation of the extruders with the highest possible power factor is also significant in energy saving.

Rosato et al. [9] reported that the energy efficiency of an extruder is dependent upon the factors such as torque available on the screw, screw rotational speed, heat control and material being processed. They mentioned that energy losses from $3-20 \%$ can occur and the drive system is responsible for the major portion of these losses. However, they stated that plastics have the lowest specific energy requirement for their manufacture, fabrications of products and recycling compared to other conventional raw materials.

Barlow [10] argued that $1 / 3$ of a typical extrusion plant energy consumption can be attributed to the motors. Furthermore, he stated that the most older extrusion machines are using DC motors (typical full speed and full load efficiency 90\%) and a recommendation was made to replace DC motors with AC vector-controlled motors (typical full speed and full load efficiency 95\%) to achieve better energy performance. He mentioned that these typical efficiency figures further reduce as the motor is running out of its rated speed/load, and these reductions can be up to $75 \%$ and $85 \%$ for DC and AC motors, respectively. Motor efficiency is further reduced as it becomes older. Thus, minimising unnecessary energy usage by selecting optimum processing conditions is also important to achieve a better overall process efficiency as machine attributed inefficiency may not be controlled or eliminated.

Work presented by Cantor [11] measured extruder specific energy consumption (SEC) together with the contributions of the motor and each heater zone to the extruder SEC (SEC is the power consumed to produce a unit amount of extrudate). Experiments were carried out at five different speeds utilising three different screw designs and two materials. The extruder SEC was shown to be reduced as speed increased. SEC of the zone heaters also reduced with the speed. Moreover, the contribution of heaters towards the extruder SEC was higher at low speeds than the drive motor and this trend changed as screw speed increased. The author claimed that the heaters waste over $95 \%$ of the supplied energy and hence suggested the need to consider for new barrel heating technologies.

A number of other authors [12], [13] have discussed the advantages of replacing the DC motors with AC motor drives to benefit energy consumption. They performed experiments on the same extruder with AC and DC motors and found that a considerable amount of energy saving can be achieved with AC motors compared to DC motors. As they claimed, the replacement of old DC motors with new vector-controlled $\mathrm{AC}$ motor drives provide significant benefits in the long-run although the initial capital cost is higher for AC motors.

As stated by Drury [14], in extrusion there is little potential of useful recovery of rejected energy as these are largely released to air or water. Moreover, the authors argued that over $40 \%$ from the energy supplied to a small scale extruder is rejected without being effectively used through radiation, convection, conduction, drive/transmission losses, etc.

Other works [15]-[19] have also focused on energy consumption related issues in polymer extrusion.

\section{Effect of process settings on extruder energy consumption}

In addition to the drive motor, other devices attached to the extruder such as barrel heaters, cooling fans, gear pumps, pelletizers, etc, should operate with their optimum energy efficiency for the energy efficient operation of the whole extrusion plant. Rauwendaal [3] argued that the extruder power consumption depends on both material and machine geometry. Work by Rasid and Wood [20] found that the solids conveying zone barrel temperature has the greatest influence on the energy consumption of the extruder.

Kelly et al. [21] and Sorroche et al. [22] have shown that the extruder SEC reduces as screw speed increases despite the differences in the screw geometry. However, the SEC differed with screw geometry and the material being processed within the same operating conditions. Moreover, a barrier flighted screw had the lowest energy consumption compared to a gradual compression and a rapid compression screws. At the same experiment, they found that melt temperature fluctuations increased as screw speed increased. Therefore, it seems that achieving both an energy efficient operation and a high quality melt output with desirable output rates are still challenging despite significant developments in the polymer extrusion field over the last few decades.

Previous work by the present authors [6] found that the motor energy consumption increased as the screw speed increased while the motor SEC decreased for a single screw extruder. Moreover, they found that the barrel set tempera- 
tures had a slight effect on the motor energy consumption and the motor SEC. The motor SEC reduced as the barrel zone temperatures increased. However, running an extruder at a higher speed with higher energy efficient conditions may not be realistic as the required thermal quality of the melt output may not be achieved due to the reduction of material residence time. The selection of an optimum operating point in terms of energy efficiency and thermal quality may be the most important requirement for the current industry.

\section{Modelling of the extruder energy consumption}

From the literature, it is clear that only a limited amount of work have been attempted to develop model/s to predict the total energy consumption of an extruder or its individual components. Mallouk and Mckelvey [23] proposed a theoretical expression to derive the energy requirements of melting section of extruders under the conditions of Newtonian flow, constant screw channel dimensions and isothermal operation. Screw dimensions, screw speed, die pressure and melt viscosity were taken into account for calculating the energy. As they mentioned, the total extruder energy demand is the sum of the energy consumed in helical screw channel and that dissipated between the screw land and the barrel wall.

Wilczynski [24] presented a computer model for single screw extrusion to predict the mass flow rate; pressure and temperature profiles along the extruder screw channel and in the die; the solid bed profile; and the power consumption based on the rheological properties of the polymer, the screw, the hopper and die geometry and dimensions, and the process operating conditions (i.e. speed and barrel set temperature). However, no details were given of the predicted power consumption. Lai and Yu [25] proposed a mathematical model to calculate the energy consumption per channel in single screw extruders based on the screw speed, material viscosity and a few other machine geometrical parameters. However, no details were provided on the model performance.

Previous work by the present authors [26] proposed nonlinear polynomial models to predict the motor energy consumption of a single screw extruder over different processing conditions and materials. Screw speed was identified as the most critical parameter affecting the extruder motor energy consumption while the barrel set temperatures also showed a slight effect. Of the barrel zones, the effects of the feed zone temperature were more significant than other two zones.

The development of models to predict the extruder total energy consumption based on the processing conditions may help operators to select the most desirable operating conditions by eliminating possible excessive energy demands (i.e. situations in which the energy is more than that required for the process). Particularly, models based on the motor energy consumption may be useful for selecting the most desirable and highest possible processing speed (the higher the speed the higher the energy efficiency). However, the selection of energy efficient process settings should coincide with good thermal stability as well which is still a challenging task within the industry. Therefore, studies to identify the combined effects of process settings on both energy efficiency and thermal stability would be more desirable to select a more attractive operating point with better overall process efficiency. In this work, the total extruder power consumption was modelled as a function of key process variables (e.g. screw speed, barrel/die set temperatures) and some other functional process parameters such as melt temperature.

\section{EQUiPMENT \& PROCEDURE}

All measurements were carried out on a $63.5 \mathrm{~mm}$ diameter (D) single screw extruder. A gradual compression (GC) screw with 3:1 compression ratio, a tapered rapid compression (RC) screw with 3:1 compression ratio and a barrier flighted (BF) screw with a spiral Maddock mixer and 2.5:1 compression ratio were used to process the material. The extruder was fitted with a $38 \mathrm{~mm}$ diameter adapter by using a clamp ring prior to a short $6 \mathrm{~mm}$ diameter capillary die as shown in Figure 2. The extruder barrel has four separate temperature zones (each fitted with a $4 \mathrm{~kW}$ heater) and another three separate temperature zones at the clamp ring, adapter and die. The extruder drive is a horizontal type separately excited direct current motor which has ratings: $460 \mathrm{Vdc}, 30.5 \mathrm{~kW}$, at speed $1600 \mathrm{rpm}$. The motor and screw are connected through a fixed gearbox with a ratio of 13.6:1, and according to the manufacturers' information the gearbox efficiency is relatively constant at all speeds $(\sim 96 \%)$.

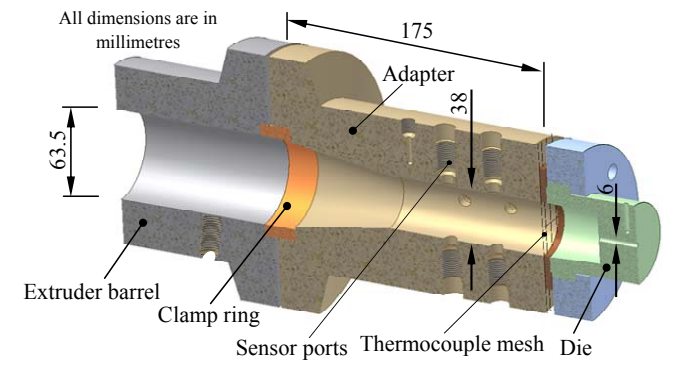

Fig. 2. The arrangement and the dimensions of the apparatus

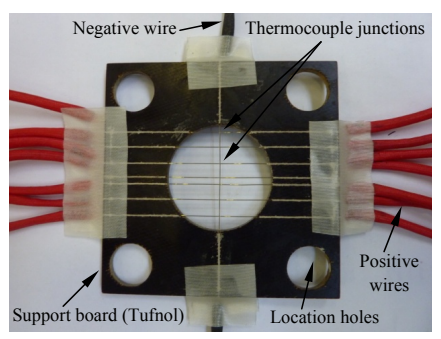

Fig. 3. The thermocouple mesh arrangement

Melt pressure was recorded by a Dynisco TPT463E pressure transducer close to the screw tip to observe the functional quality of the process. The total extruder power and motor power were measured using a Hioki and an Acuvim IIE three-phase power meters, respectively. Melt temperatures of the different radial locations of the melt flow at the end of the adapter were measured using a thermocouple mesh [27] placed in-between the adapter and die as shown in Figure 2. A thermocouple mesh with seven junctions (i.e. with 7 positive and 1 negative thermocouple wires) was used in this study and mesh junctions were placed asymmetrically across the melt flow along the diameter of the mesh as 
shown in Figure 3 (distance from the melt flow centreline to each radial position: $0 \mathrm{~mm}, 3 \mathrm{~mm}, 4.5 \mathrm{~mm}, 8.8 \mathrm{~mm}, 11 \mathrm{~mm}$, $14.7 \mathrm{~mm}$ and $16.5 \mathrm{~mm}$ ). The minimum and maximum melt temperatures across the melt flow at each screw speed were determined based on these seven temperature measurements.

A programme developed in LabVIEW was used to communicate between the instruments and a PC. All signals were acquired at $10 \mathrm{~Hz}$ using a 16-bit DAQ card, National Instruments (NI) PCI-6035E, through a NI TC-2095 thermocouple connector box and a NI low-noise SCXI-1000 connector box.

A. Materials and experimental conditions

Experimental trials were carried out on a virgin high density polyethylene (HDPE), Rigidex HD5050EA (density: $0.950 \mathrm{~g} / \mathrm{cm}^{3}$ and melt flow index: $4.0 \mathrm{~g} / 10 \mathrm{~min}$ ). The extruder barrel temperature settings were fixed as described in Table I under three different set conditions denoted as A (low temperature), B (medium temperature) and C (high temperature).

TABLE I

EXTRUDER BARREL TEMPERATURE SETTINGS

\begin{tabular}{|c|c|c|c|c|c|c|c|}
\hline \multirow{2}{*}{$\begin{array}{c}\text { Temperature } \\
\text { settings }\end{array}$} & \multicolumn{7}{|c|}{ Set temperatures $\left({ }^{\circ} \mathrm{C}\right)$} \\
\cline { 2 - 8 } & 1 & 2 & 3 & 4 & & & \\
\hline A & 130 & 155 & 165 & 180 & 180 & 180 & 180 \\
\hline B & 140 & 170 & 185 & 200 & 200 & 200 & 200 \\
\hline C & 150 & 185 & 205 & 220 & 220 & 220 & 220 \\
\hline
\end{tabular}

Three different experimental trails were carried out with the three screw geometries and the data was collected at Orpm for a small time period. Then, the screw speed was adjusted from $10 \mathrm{rpm}$ to $90 \mathrm{rpm}$ in steps of 20rpm. All data were recorded continuously whilst the extruder was allowed to stabilise at each screw speed.

\section{RESULTS AND DISCUSSION}

\section{A. Experimentally measured extruder energy consumption}

The experimentally measured average values of the total extruder power consumption with different screws and processing conditions are shown in Figure 4-(a). Figure legends are shown in the format of screw-set temperature condition. Also, the specific energy consumption of the extruder under the same operating conditions is shown in Figure 4-(b). These

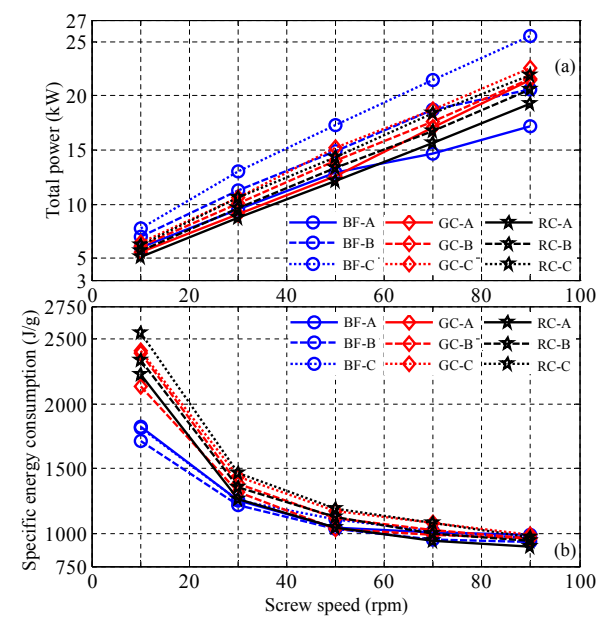

Fig. 4. Extruder total power consumption and specific energy consumption (SEC) at different processing conditions (i.e. average values) graphs show that the extruder energy demand depends on the screw speed, barrel set temperatures and screw geometry in a complex manner. The experimental observations showed that the extruder total power was highly varying over the time where these variations were larger than $15 \mathrm{~kW}$ at some processing conditions. Then, a separate experimental trial was carried out to check both the total extruder power and motor power while observing the effects of barrel heaters (together with cooling fans) on the total extruder power. Both power signals were observed together with the RC screw and after a few minutes all the heaters (with cooling fans) were turned-off as shown in Figure 5. In fact, it is clear that the

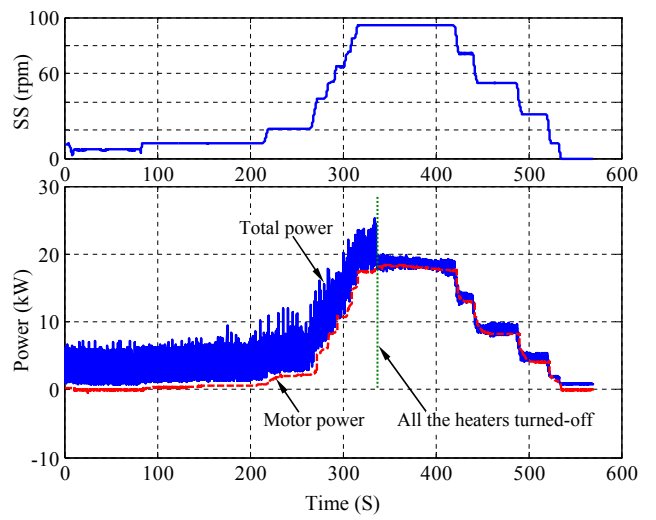

Fig. 5. Screw speed (SS), motor power and total power over the time barrel heaters and cooling fans are responsible for the most of the variations induced in the total extruder power. Figure 5 confirms that the drive motor and barrel heaters are the dominant power demanding components of the extruder. These results suggest that the extruder energy demand is complexly coupled among machine/material/process parameters.

\section{B. Empirical modelling of extruder total energy consumption}

Here, the main aim was to develop a model to predict the total extruder power $\left(E_{p}\right)$ as a function of major process variables and functional process parameters. Of the process variables, screw speed $\left(\omega_{s c}\right)$ and barrel set temperatures $\left(T_{1}\right.$, $T_{2}, T_{3}, T_{4}$ ) were selected as the model inputs. Among the functional process parameters the difference between the maximum and minimum melt temperatures of the output melt flow cross-section $\left(T_{d}\right)$ were selected. Then, the total power demand of the extruder can be given as:

$$
E_{p}=f\left(\omega_{s c}, T_{d}, T_{1}, T_{2}, T_{3}, T_{4}\right)
$$

Overall, this is a multi-input-single-output (MISO) model which has six inputs to predict the total extruder energy consumption at a given condition and the model structure is shown in Figure 6. As shown, the set temperatures of the

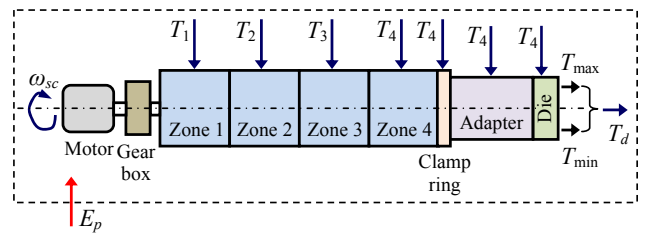

Fig. 6. Extruder model with the selected inputs and output 
clamp ring, the adapter and the die were always equal to $T_{4}$ during the experiments and hence these were considered as a signal input. If these set values are different from $T_{4}$, it is possible to add them as three different model inputs.

In this study, a two-stage algorithm [28] was employed in the selection and refinement of the models with a linear-inthe-parameters structure. In the first stage, a fast recursive algorithm was used for the selection of the model structure and for estimation of the model parameters. Then, in the second stage a backward model refinement procedure was carried out to eliminate non-significant terms to build up a compact model. The significance of each selected model term was reviewed and compared with those remaining in the candidate term pool and all insignificant terms were replaced, leading to improved performance without increasing the model size. The authors have used the same technique for the modelling of the die melt temperature profile [29]-[32], melt pressure [33] and motor power consumption [26] in polymer extrusion, and good results have been achieved.

Separate models were developed for each screw by arranging the data in the order of set temperature conditions A-B-C (see Table I). After studying a number of model combinations (i.e. with different number of terms and orders), $2^{\text {nd }}$ order 12 terms models were chosen for further study and are given in (2), (3) and (4) for the BF, GC and RC screws, respectively.

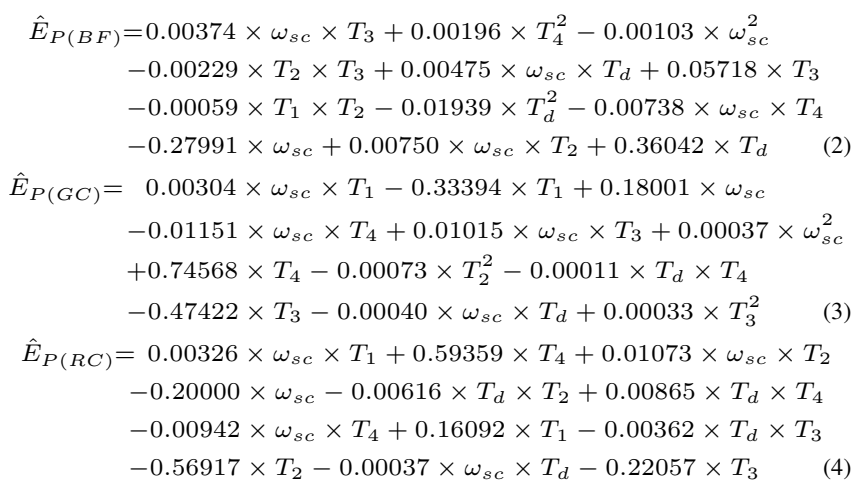

In fact, it is possible to develop lower or higher order models with a different number of terms, if required. Then, a suitable model can be selected based on the required model accuracy and the type of the application.

C. Comparison of experimental and model predicted total extruder energy consumption

Experimentally measured and model predicted total power values are shown in Figure 7-(a), (b) and (c) for BF, RC and GC screws, respectively. Additionally, the total extruder power was estimated for the GC screw (i.e. under the same processing conditions used for the experiments) by using the commercially available Compuplast extrusion simulation software and the estimated values are shown in Figure 7-(c). Figure legends are in the format of screw-set temperature condition and the terms EXP, MOD and COM are used to denote experimental, model prediction and computer simulation conditions, respectively. For modelling, all experimental data for each screw which covers a board operating window (i.e. 5 speeds, 3 set temperatures) were fit into a single model. However, it is evident that the experimental measurements and model predictions exhibited a good agreement. The largest

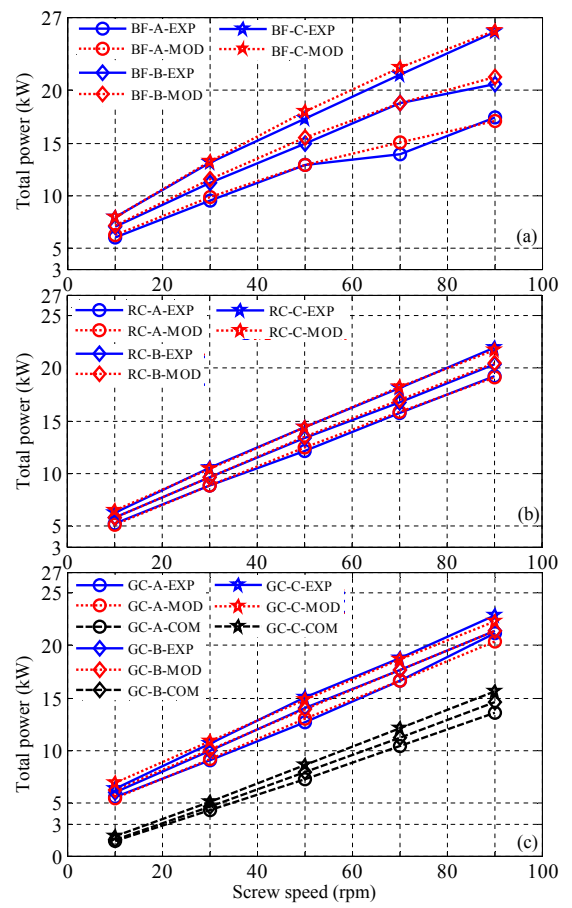

Fig. 7. Experimentally measured and model predicted total extruder power: (a)- BF screw, (b) - RC screw, (c) - GC screw

difference between the experimental and model predicted values can be seen with the BF screw at 70rpm under the set temperature condition A. Although the experimental and model predicted values show a good agreement, the total power predicted by the simulation software shows a large lagging offset with the experimental values.

As the predictions of the proposed models are good in accuracy, these can be used to identify significant process parameters in terms of extruder total power consumption based on the screw geometry. By observing the models (i.e. coefficients and variables), it is clear that the screw speed has the most significant impact on the extruder total power demand as confirmed by the experimental results as well. Of the barrel zone temperatures, $T_{4}$ which pertains to the metering zone has shown the highest influence on the total power demand with all the screws for this particular material. The second most influential barrel zone temperatures were identified as $T_{2}, T_{1}$ and $T_{2}$ for the $\mathrm{BF}, \mathrm{GC}$ and RC screws, respectively. Then, the proposed models were used to check

TABLE II

CHANGES TO THE LEVEL OF THE TOTAL POWER AS EACH BARREL ZONE TEMPERATURE INCREASED BY $5^{\circ} \mathrm{C}$ FROM THE SET CONDITION B

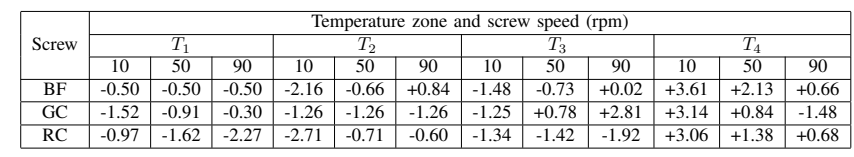

the effects on extruder total power demand after increasing each barrel zone set temperature by $5^{\circ} \mathrm{C}$ (i.e. from set condition B) while other set conditions remained constant, and the quantity of change of the energy demand in $\mathrm{kW}$ (due to the applied change) is shown in Table II. These values 
clearly explain the complexity of the relationship between the process energy demand and other relevant parameters. Evidently, the extruder total power demand differs significantly depending on the screw geometry, speed, set temperature and the material being processed. Obviously, it is extremely difficult to understand the nature of a such complex behavior by simply monitoring power values on a sensor display. Thus, the models proposed can be used to obtain a detailed understanding on the pattern of process energy demand and to identify the major influential process parameters.

\section{CONCLUSIONS AND FUTURE WORK}

\section{A. Conclusions}

Improvements to process energy efficiency is an important requirement in polymer extrusion. However, this should be achieved while maintaining good melt quality. Detailed understanding of the process energy demand and losses, i.e. the knowledge on where, when, why and how much of energy is used in the plant, is highly useful in energy optimization. The understanding of the effects of the major process variables and machine geometry on extruder's total energy demand is invaluable and hence empirical models were proposed to predict the extruder's total energy demand based on the readily measurable process variables and functional parameters. The proposed models show a promising agreement with the experimental measurements made over a wide operating window. Models show that screw speed had the greatest influence on the total energy demand of the extruder despite the differences in screw geometry used for material processing. In fact, these type of models should be useful in exploring the influence of individual parameters (i.e. machine, material and process) and their combined effects on the extruder total energy demand in detail. Such investigations can aid optimisation of the process energy efficiency while achieving other required processing factors.

\section{B. Future Work}

In future work, these models will be used to further study process energy consumption pattern/behaviour. Also, the research will be extended to observe motor and heater powers together with the total power. A number of different materials will be used to understand the process energy usage and to explore possible relationships between process thermal stability and energy usage. These details should help to improve the accuracy of these proposed empirical models by adding other possible machine and material related parameters. Additionally, an attempt will be made to develop a physical model relating to extruder total energy consumption.

\section{REFERENCES}

[1] Available at: http://www.plasticseurope.org/, Last viewed: 10/10/2012.

[2] J. Vlachopoulos and D. Strutt, "Overview: Polymer processing," Mater. Sci. Technol., vol. 19, pp. 1161-1169, 2003.

[3] C. Rauwendaal, Polymer Extrusion, 4th ed. Hanser-Munich, 2001.

[4] C. Abeykoon, Polymer Extrusion: A Study on Thermal Monitoring Techniques and Melting Issues. Lap Lambert Publishing-Verlag, 2012.

[5] S. Chapman, Electrical machinary fundemantals. McGraw-Hill, 2005.

[6] C. Abeykoon, M. McAfee, S. Thompson, K. Li, A. L. Kelly, and E. C. Brown, "Investigation of torque fluctuations in extrusion through monitoring of motor variables," Proc. of 26th PPS Annual Europe/Africa regional meeting, Larnaca, Cyprus, 2009, paper No: 22-O.
[7] C. Abeykoon, M. McAfee, K. Li, P. J. Martin, and A. L. Kelly, "The inferential monitoring of screw load torque to predict process fluctuations in polymer extrusion," J. Mater. Process. Technol., vol. 211, no. 12, pp. 1907-1918, 2011.

[8] G. A. Kruder and R. E. Nunn, "Optimizing energy utilization in extrusion processing," SPE ANTEC Tech. Papers, pp. 648-652, 1981.

[9] D. V. Rosato, N. R. Schott, D. V. Rosato, and M. G. Rosato, Plastics engineering, manufacturing \& data handbook: Fundamental and processes. Kluwer Academic Publishers, 2001, vol. 2.

[10] S. Barlow, "Reducing electrical energy costs for extrusion processes," SPE ANTEC Tech. Papers, pp. 1157-1162, 2009.

[11] K. M. Cantor, "Analyzing extruder energy consumption," SPE ANTEC Tech. Papers, vol. 2, pp. 1300-1306, 2010.

[12] R. A. Sfeir, "Measured savings of DC to AC drive retrofit in plastic extrusion," Proc. of the 13th Industrial Energy Technology Conference, New Orleans, USA, 2008.

[13] "Extruder line updated with ac vector drives," Available at: http: //www.yaskawa.com/site/dmdrive.nsf, Last viewed: 10/08/2012.

[14] B. Drury, The control techniques drives and controls handbook. The Institution of Electrical Engineers, London-UK, 2010, pp 308-312.

[15] J. V. DeJuneas, "How to reduce electrical energy in the extrusion process," TAPPI Pap Synthesis Conference, pp. 49-50, 1975.

[16] C. I. Chung, "Energy efficinecy in single screw extrusion," SPE ANTEC Tech. Papers, pp. 919-920, 1983.

[17] J. M. McKelvey, "Energy utilisation in extrusion," Adv. Polym. Tech., vol. 3, pp. 205-211, 1983.

[18] T. W. Womer, W. S. Smith, and R. P. Wheeler, "Comparison of two different cooling methods for extrusion processes," SPE ANTEC Tech. Papers, pp. 796-801, 2006.

[19] J. Anderson, C. Rauwendaal, and M. del P. Noriega, "Troubleshooting extrusion problems," SPE ANTEC Tech. Papers, pp. 127-134, 1997.

[20] R. Rasid and A. K. Wood, "Effect of process variables on melt tempearture profiles in extrusion process using single screw plastics extruder," Plast. Rubber Compos., vol. 32, no. 5, pp. 193-198, 2003.

[21] A. L. Kelly, E. C. Brown, and P. D. Coates, "The effect of screw geometry on melt temperature profile in single screw extrusion," Polym. Eng. Sci., vol. 46, no. 12, pp. 1706-1714, 2006.

[22] J. V. Sorroche, A. L. Kelly, E. C. Brown, P. D. Coates, N. Karnachi, E. Harkin-Jones, K. Li, and J. Deng, "Thermal optimisation of polymer extrusion using in-process monitoring techniques," Appl. Therm. Eng., vol. 53, no. 2, pp. 405-413, 2012.

[23] R. S. Mallouk and J. M. Mckelvey, "Power requirements of melt extruders," Ind. Eng. Chem., vol. 45, pp. 987-989, 1953.

[24] K. Wilczynski, "A computer model for single-screw plasticating extrusion," Polym. Plast. Technol. Eng., vol. 35, no. 3, pp. 449-477, 1996.

[25] E. Lai and D. W. Yu, "Modeling of the plasticating process in a single screw extruder: A fast track approach," Polym. Eng. Sci., vol. 40, no. 5, pp. 1074-1084, 2000.

[26] C. Abeykoon, M. McAfee, K. Li, P. J. Martin, J. Deng, and A. L. Kelly, "Modelling the effects of operating conditions on motor power consumption in single screw extrusion," Proc. of LSMS 2010 and ICSEE 2010, vol. 6329, no. 2, pp. 9-20, 2010.

[27] E. C. Brown, A. L. Kelly, and P. D. Coates, "Melt temperature field measurement in single screw extrusion using thermocouple meshes," Rev. Sci. Instrum., vol. 75, no. 11, pp. 4742-4748, 2004.

[28] K. Li, J. X. Peng, and E. W. Bai, "A two-stage algorithm for identification of nonlinear dynamic systems," Automatica, vol. 42, no. 7, pp. 1189-1197, 2006.

[29] C. Abeykoon, K. Li, M. McAfee, P. J. Martin, Q. Niu, A. L. Kelly, and J. Deng, "A new model based approach for the prediction and optimisation of thermal homogeneity in single screw extrusion," Control Eng. Pract., vol. 19, no. 8, pp. 862-874, 2011.

[30] C. Abeykoon, K. Li, P. J. Martin, M. McAfee, and G. W. Irwin, "Extruder melt tempeature control with fuzzy logic," Proc. of 18th IFAC World Congress, pp. 8577-8582, 2011.

[31] C. Abeykoon, "A novel model-based controller for polymer extrusion," IEEE Trans. Fuzzy Syst., 2014, DOI: 10.1109/TFUZZ2013.2293348.

[32] C. Abeykoon, "A novel soft sensor for real-time monitoring of die melt temperature profile in polymer extrusion," IEEE Trans. Ind. Electron., 2014, DOI: 10.1109/TIE.2014.2321345.

[33] C. Abeykoon, K. Li, P. J. Martin, and A. L. Kelly, "Monitoring and modelling of the effects of process settings and screw geometry on melt pressure generation in polymer extrusion," Int. J. Syst. Control Inf. Process., vol. 1, no. 1, pp. 71-88, 2012. 